\title{
Impact of process conditions on chemical solution deposited BNKT thin film electromechanical properties
}

\author{
Kyle M. Grove ${ }^{1}$ (D) Austin Fox ${ }^{1}$ - David P. Cann ${ }^{1}$. Song Won Ko ${ }^{2}$. Peter Mardilovich ${ }^{2} \cdot$ Brady J. Gibbons $^{1}$
}

Received: 12 March 2021 / Accepted: 7 June 2021

Published online: 14 September 2021

(c) The Author(s) 2021 OPEN

\begin{abstract}
Phase pure perovskite (1-x) $\mathrm{Bi}_{1 / 2} \mathrm{Na}_{1 / 2} \mathrm{TiO}_{3}-\mathrm{xBi}_{1 / 2} \mathrm{~K}_{1 / 2} \mathrm{TiO}_{3}$ (BNKT) thin films were successfully prepared via an inverse mixing order chemical solution deposition method and the impact of process conditions on film properties were observed. Process conditions evaluated included crystallization temperature and time, ramp rate, pyrolysis temperature, and cation excess. Properties measured included crystal structure, dielectric constant, dielectric loss, piezoelectric response, and ferroelectric response. A few notable trends were observed. A subtle impact on piezoelectric response was observed in films prepared using different ramp rates: $100 \mathrm{C}$ per second films $\left(\mathrm{d}_{33, \mathrm{f}}=60 \pm 5 \mathrm{pm} / \mathrm{V}\right.$ at $\left.1 \mathrm{kHz}\right), 75^{\circ} \mathrm{C}$ per second films $\left(d_{33, f}=55 \pm 5 \mathrm{pm} / \mathrm{V}\right)$ and $150 \mathrm{C}$ per second films $\left(\mathrm{d}_{33, \mathrm{f}}=50 \pm 5 \mathrm{pm} / \mathrm{V}\right)$. Films prepared using a $75^{\circ} \mathrm{C}$ per second ramp rate displayed slightly higher dielectric loss ( $\tan \delta=0.09$ at $1 \mathrm{kHz}$ ) than films prepared using a $100{ }^{\circ} \mathrm{C}$ per second ramp rate $(\tan \delta=0.07$ at $1 \mathrm{kHz})$ or $150^{\circ} \mathrm{C}$ per second ramp rate $(\tan \delta=0.05$ at $1 \mathrm{kHz})$. Pyrolysis temperatures greater than $350^{\circ} \mathrm{C}$ are necessary to burn off organics and maximize film dielectric constant. Dielectric constant increased from $450 \pm 50$ at $1 \mathrm{kHz}$ to $600 \pm 50$ at $1 \mathrm{kHz}$ by increasing pyrolysis temperature from 300 to $400{ }^{\circ} \mathrm{C}$. Excess cation amounts (for compositional control) were also evaluated and it was found films with higher amounts of $\mathrm{Na}$ and $\mathrm{K}$ excess compared to bismuth excess displayed an increase in $\mathrm{d}_{33, \mathrm{f}}$ of about $10 \mathrm{pm} / \mathrm{V}$ compared to films prepared with equivalent $\mathrm{Bi}$ and $\mathrm{Na}$ and $\mathrm{K}$ excess amounts.
\end{abstract}

\section{Article highlights}

- Impact of processing conditions on inverse mixing order chemical solution deposited bismuth based thin films.
- Dielectric, piezoelectric, and ferroelectric properties of thin film bismuth sodium titanate-bismuth potassium titanate thin films.

- Developing lead-free piezoelectric actuator materials.

Keywords Thin Films · BNKT · Process Optimization · Piezoelectric · Ferroelectric · Dielectric · Lead-Free

MSC $74 \mathrm{~K} 35 \cdot 74 \mathrm{C} 05 \cdot 82 \mathrm{D} 45$

Electronic supplementary material The online version of this article (https://doi.org/10.1007/s42452-021-04692-4) contains supplementary material, which is available to authorized users.

Kyle M. Grove, groveky@oregonstate.edu; Austin Fox, austin.fox@qorvo.com; David P. Cann, cann@oregonstate.edu; Song Won Ko, ksw741@gmail.com; Peter Mardilovich, peter.mardilovich@gmail.com; Brady J. Gibbons, brady.gibbons@oregonstate.edu |'Materials Science, Oregon State University, Corvallis, USA. ${ }^{2}$ Xaar PIc, Cambridge, UK

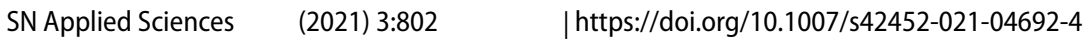




\section{Introduction}

Piezoelectric materials are those with the innate ability to convert mechanical energy to electrical energy and vice versa. They are used in a variety of applications including actuators, sensors, filters, resonators, and microelectromechanical systems (MEMS). The current industry standard piezoelectric materials, such as lead zirconate titanate (PZT), contain lead. Legislative restrictions on lead content in waste streams, including the Restriction of Hazardous Substances (RoHS) in the European Union are inspiring development of alternative lead-free piezoelectric materials [1-4]. A commonly used method for discovering new lead-free piezoelectric materials is to search for perovskite systems that display a morphotropic phase boundary (MPB) like that found in PZT at $52 \%$ lead zirconate and $48 \%$ lead titanate. One candidate material identified using this method is (1-x) $\mathrm{Bi}_{1 / 2} \mathrm{Na}_{1 / 2} \mathrm{TiO}_{3}-\mathrm{XBi}_{1 / 2} \mathrm{~K}_{1 / 2} \mathrm{TiO}_{1 / 2}$ (BNKT) which displays a relatively large piezoelectric response making it a material of interest for piezoelectric actuator applications. The BNKT system displays a MPB between $\mathrm{x}=0.16$ and $\mathrm{x}=0.20[2,3,5]$.

A considerable number of bulk ceramic studies have optimized the piezoelectric properties of BNKT by introducing disorder via the inclusion of a third endmember such as $\mathrm{BiZn}_{1 / 2} \mathrm{Ti}_{1 / 2} \mathrm{O}_{3}(\mathrm{BZT}), \mathrm{BiMg}_{1 / 2} \mathrm{Ti}_{1 / 2} \mathrm{O}_{3}(\mathrm{BMgT})$, or $\mathrm{K}_{1 / 2} \mathrm{Na}_{1 / 2} \mathrm{NbO}_{3}$ (KNN) [5-9]. The increase in piezoelectric properties caused by the addition of a third endmember is often associated with an increase in structural disorder and a transition from non-ergodic to ergodic relaxor behavior. There are considerably fewer studies on thin film embodiments compared to bulk embodiments of BNKT. The exact compositions and process techniques in these existing studies vary considerably. The primary deposition methods explored are chemical solution deposition and pulsed laser deposition [10-14]. Many BNKT based thin film studies do not report piezoelectric properties and most that do use quantitative piezoelectric force microscopy (PFM) which, unlike dual beam laser interferometry (DBLI), are susceptible to error from substrate bowing and electrostatic interactions between the PFM tip and the film [15-18]. Ternary BNKT based thin films have not displayed the same increase in piezoelectric response or the change in relaxor behavior that is characteristic of bulk BNKT based ternary systems $[12,18,19]$. Jeon et al. suggests the difference between thin film and bulk behavior could be caused by large substrate clamping stresses or chemical inhomogeneity through the thickness of the film [12]. In chemical solution deposited thin films, processing conditions are known to have considerable impact on film stoichiometry, defect concentration, phase purity, stress state, and microstructure all of which can have an impact on key properties including dielectric constant, dielectric loss, ferroelectric response, and piezoelectric strain [12, $13,20-26]$. Inverse mixing order chemical solution deposition techniques are of particular interest since they can be easily scaled into industrial applications. This study focuses on improving understanding of process-property relationships for BNKT chemical solution deposition processes by observing how various process conditions can impact thin film crystallinity, dielectric properties, ferroelectric response, and piezoelectric response.

\section{Experimental}

Solutions were synthesized using an inverse mixing order (IMO) solution processing route $[11,13,27]$. The precursors used in the process were bismuth (III) acetate $(99.9999 \%$, Alfa Aesar), sodium acetate trihydrate (99\%, Macron), potassium acetate (99\%, Macron), and titanium (IV) isopropoxide $(97 \%, \mathrm{TCl})$. Precursors and solvents are weighed in amounts to generate a $0.5 \mathrm{M}$ solution. Bismuth acetate is first dissolved in propionic acid at room temperature by stirring for approximately one hour. Sodium acetate trihydrate and potassium acetate are weighed in a dry nitrogen atmosphere and dissolved in methanol by stirring at room temperature for approximately one hour. The titanium isopropoxide is weighed and chelated in a dry nitrogen atmosphere using a mixture of acetic acid and a small amount of propionic acid. After each solution was stirred for approximately one hour an appropriate amount of the bismuth precursor solution is weighed into the chelated titanium solution. This solution is mixed for one hour before the sodium and potassium precursor solution is weighed into the titanium/bismuth solution mixture. After the addition of the sodium and potassium precursor the final solution is mixed for ten to fifteen hours to ensure complete homogeneity before usage. Solution compositions and excess amounts are controlled by adjusting measured amounts of precursors during the solution synthesis process. All solutions used in this study were $80 \%$ BNT and 20\% BKT.

The films were deposited on platinized silicon substrates $\left(\mathrm{Pt}(110 \mathrm{~nm}) / \mathrm{TiO}_{\mathrm{x}}(30 \mathrm{~nm}) / \mathrm{SiO}_{2}(500 \mathrm{~nm}) / \mathrm{Si}\right.$, MEMS Exchange). The substrates were cleaned through a threestep sonication process in acetone, methanol, and isopropyl alcohol for five minutes each. Afterwards, the substrates are dried with a dry nitrogen gun and heated to $350^{\circ} \mathrm{C}$ for two minutes on a hotplate in air to burn off any residual organic contaminants. The films were then wetted with the precursor solution and spin cast at $3000 \mathrm{rpm}$ for $30 \mathrm{~s}$. The pre-crystallization heat treatment process 
includes a one-minute dry at $100{ }^{\circ} \mathrm{C}$ and a four-minute pyrolysis at $350{ }^{\circ} \mathrm{C}$ on separate hotplates. Finally, a rapid thermal annealing/crystallization (RTA) step is performed at $700{ }^{\circ} \mathrm{C}$ for five minutes with a $100{ }^{\circ} \mathrm{C}$ per second ramp rate and two standard liters per minute (SLPM) of UHP oxygen flow. Note that times and temperatures listed in this section describe the general synthesis process. For samples prepared using modifications to the standard process the differences will be clearly stated. For a $0.5 \mathrm{M}$ solution deposited using the above standard conditions the typical per layer thickness is approximately $70 \mathrm{~nm}$, confirmed using cross sectional scanning electron microscopy (SEM) and spectroscopic ellipsometry. All films in this study were 3 layers $(210 \mathrm{~nm})$ thick. For samples measured on the aixACCT DBLI a polishing process was completed on the back of the substrate to create a smooth reflective surface. The polishing process used 15, 5, 1 and $0.3 \mu \mathrm{m}$ lapping paper. Films were protected using a layer of Kapton tape. Before deposition of electrodes a $15-\min 400{ }^{\circ} \mathrm{C}$ heat cleaning was performed to remove any residue remaining from the tape. To prepare samples for electrical characterization, $\mathrm{Pt}$ top electrodes were DC sputtered through a shadow mask. The diameter of the electrode holes on the shadow mask was $0.675 \mathrm{~mm}$ which is approximately equivalent to overall film/substrate thickness $[28,29]$. It should be noted that the actual diameter of the sputtered platinum electrodes may be slightly larger/smaller than the size of the holes on the shadow mask. To expose the bottom electrode, a corner of the film was etched with 10\% hydrofluoric acid using a cotton tipped applicator. Crystallinity and phase purity were verified using a Bruker D8 Discover with CuK radiation. An HP 4192A impedance analyzer was used to measure dielectric constant and $\tan \delta$ over a frequency range of 0.1 to $10 \mathrm{kHz}$ with an oscillation voltage of $50 \mathrm{mV}$. Polarization-electric filed (P-E) and strain loops were taken concurrently using an aixACCT DBLI system. Strain and P-E loops were taken at $1 \mathrm{kHz}$ with fields up to $600 \mathrm{kV} / \mathrm{cm}$. For most films prepared in this work, multiple measurements were performed using different top electrodes. In general, there was very little variation between measurements and the data presented in this paper are representative of the trends identified for each process condition. The supplementary data includes a summary table with ranges of observed experimental values.

\section{Results and discussion}

\subsection{Deposition of perovskite BNKT thin films.}

Depositing BNKT based perovskite thin films on platinized silicon wafers poses numerous challenges. Sodium, potassium, and bismuth are all highly volatile cations, so steps need to be taken to control stoichiometry during high temperature processing. Cations also diffuse into the platinum on the $\mathrm{Pt} / \mathrm{TiO}_{2} / \mathrm{SiO}_{2}$ substrate which can impact film stoichiometry. Volatilization and diffusion occur at different rates and could cause a chemical inhomogeneity through the thickness of the films. Additionally, BNT based thin films have complex thermal expansion properties [28] which do not match those of the platinized silicon wafers on which they are deposited. This can cause mechanical issues during high temperature processing including high residual stress states that can impact piezoelectric and ferroelectric properties and/or cause cracking in thicker films.

In this work several processing strategies were employed to determine their impact on the issues described above. Excess cations were included to compensate for volatilization and diffusion. In general films were prepared with greater amounts of $\mathrm{Na}$ and $\mathrm{K}$ excess compared to $\mathrm{Bi}$ excess since $\mathrm{Na}$ and $\mathrm{K}$ are more volatile than $\mathrm{Bi}$ [30]. Crystallization conditions including temperature, time, and ramp rate were adjusted and their impact on film properties observed. In general crystallization temperature and time were kept as low and short as possible without causing a detriment to film properties to minimize the effects of diffusion, volatilization, and thermal expansion mismatch. Several ramp rates were tested since thin films nucleation and growth mechanisms have been shown to be impacted by ramp rate in lead based material systems [31, 32]. Finally, pyrolysis conditions were also evaluated since the gradual volatilization of organics is vital to ensure dense films are formed. It was found that films formed largely phase pure perovskites over a large range of process conditions and with additional process optimization completely phase pure films were also synthesized.

Phase pure perovskite films were successfully formed at crystallization temperatures of $650^{\circ} \mathrm{C}$ and $700^{\circ} \mathrm{C}$ using a five minute crystallization hold time with a $100^{\circ} \mathrm{C}$ per second ramp rate and four minute pyrolysis at $350^{\circ} \mathrm{C}$. Figure 1 displays XRD patterns for films crystallized at 650, 700 , and $800^{\circ} \mathrm{C}$.

From the XRD pattern, films crystallized at 650 and $700{ }^{\circ} \mathrm{C}$ were phase pure perovskites. The XRD curves display no tetragonal or rhombohedral peak splitting potentially indicating a pseudo-cubic phase is stabilized by residual stresses in the film. It is also possible the lab XRD scans do not have sufficient resolution to detect peak splitting in the tetragonal (200) or rhombohedral (211), (111) peaks in thin films. Ultimately, $700{ }^{\circ} \mathrm{C}$ was chosen as the optimal annealing temperature to minimize the thermal budget and to promote complete crystallization and densification. Once a process for depositing phase pure BNKT perovskites was determined, process optimization experiments were performed. During process optimization only one condition was 


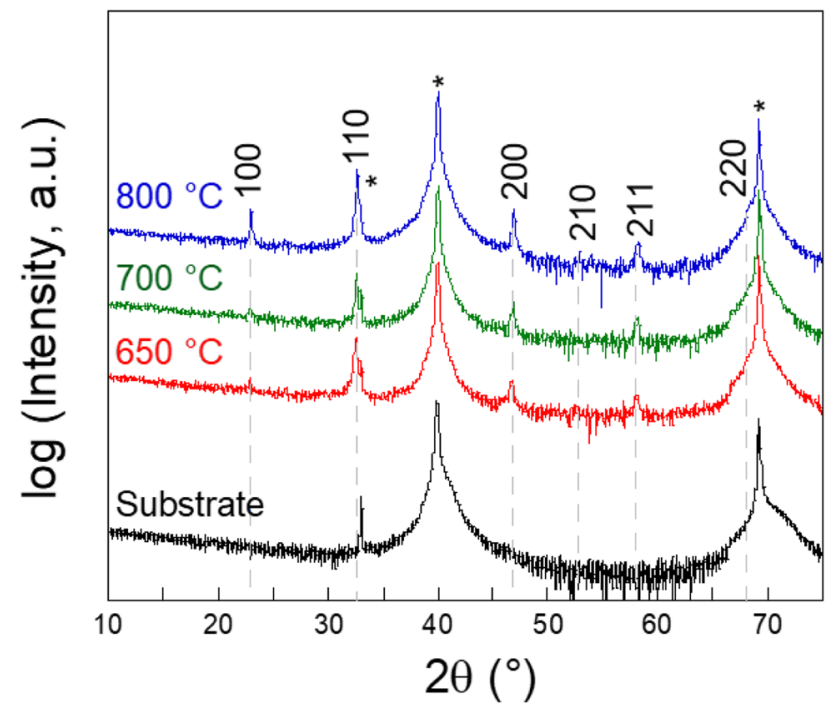

Fig. 1 Reference XRD scan of a substrate with no film deposited and scans of $210 \mathrm{~nm}$ films annealed at 650,700 and $800{ }^{\circ} \mathrm{C}$ with present BNKT peaks labeled (Substrate peaks are marked by $a *$ symbol)

varied at a time and all films were synthesized using the following general conditions: drying at $100^{\circ} \mathrm{C}$ for one minute, pyrolysis at $350^{\circ} \mathrm{C}$ for four minute and crystallization at $700^{\circ} \mathrm{C}$ for 5 min with $100^{\circ} \mathrm{C}$ per second ramp rate and 2 SLPM oxygen flow. Each optimization experiment was repeated two to three times to ensure repeatability and the data presented here are characteristic of the trends observed. Films were deposited on $1 \mathrm{~cm}$ by $1 \mathrm{~cm}$ coupons cut from an 8 " wafer, for each set of conditions during each optimization experiment and at least 5 measurable electrodes were tested on each wafer. Each film had three spin cast layers for a total film thickness of $210 \mathrm{~nm}$. Piezoelectric response, measured as $d_{33, f}$ typically varied by no more than $\pm 5 \mathrm{pm} / \mathrm{V}$ between electrodes on the same wafer, dielectric constant also remained relatively stable, varying no more than \pm 50 between measurable electrodes without excessively high dielectric loss. The dielectric loss values varied considerably with measurements taken between different electrodes and, in some films, a number of electrodes were shorted. In some cases, the $d_{33, f}$ values varied between batches even when process conditions were kept constant. The electromechanical data show there is no clear and simple relationship between process conditions and electromechanical properties. The $d_{33, f}$ value, similar to the dielectric constant, is sensitive to many film characteristics (microstructure, point defects, etc.) and thus the relationship between process conditions and $d_{33, f}$ is complex. As a typical example of the variation of the measured properties, $d_{33, f}$ values ranged from $50 \mathrm{pm} / \mathrm{V}$ to $80 \mathrm{pm} / \mathrm{V}$ in $0.8 \mathrm{BNT}-0.2 \mathrm{BKT}$ films processed

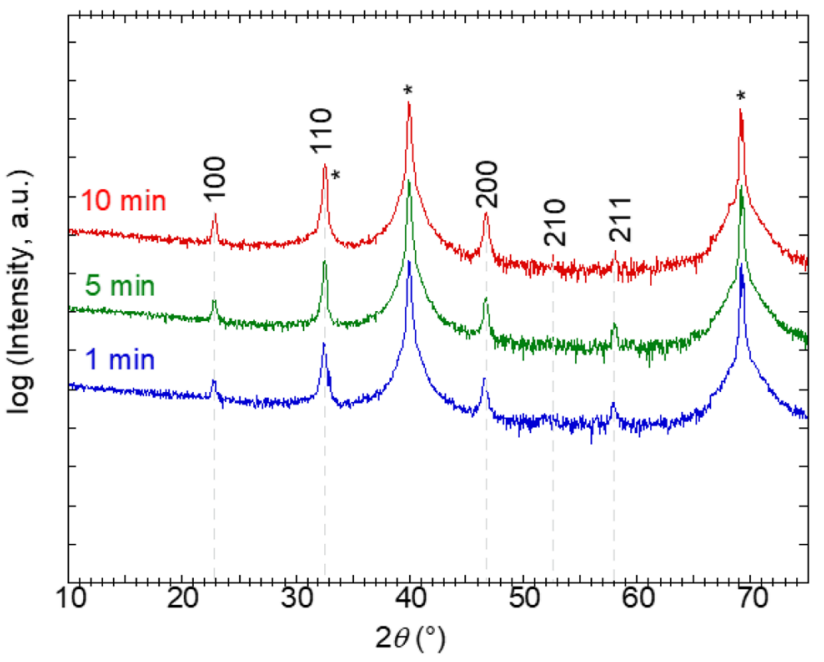

Fig. 2 XRD data for $210 \mathrm{~nm} 0.8 \mathrm{BNT}-0.2 \mathrm{BKT}$ films annealed at $1 \mathrm{~min}$, $5 \mathrm{~min}$, and $10 \mathrm{~min}$ at $700^{\circ} \mathrm{C}$ with present BNKT peaks labeled (Substrate peaks are marked by $a{ }^{*}$ symbol)

with $6 \%$ Bi excess and $12 \% \mathrm{Na}$ and $\mathrm{K}$ excess and annealed using the general process conditions described above.

\subsection{Crystallization conditions}

The hold time during crystallization can impact film properties by providing additional time for cation diffusion, volatilization, and crystallization. Three $210 \mathrm{~nm}$ films were prepared by annealing at $700^{\circ} \mathrm{C}$ for 1,5 , and $10 \mathrm{~min}$ with a $100^{\circ} \mathrm{C}$ per second ramp rate. Figure 2 shows XRD scans for all three samples.

No obvious trend in film crystallinity appeared with time, all three films developed phase pure randomly oriented perovskite structures. In thin film perovskite materials, crystallization typically happens very fast so the kinetics of crystallization is impacted more by ramp rate and maximum temperature than hold time [31, 33].

Figure 3 displays dielectric constant and loss vs. frequency data for films prepared at all three hold times. An increase in dielectric constant with increasing crystallization time was observed and the film held for one minute displayed a considerably higher dielectric loss than films prepared with longer hold times $(\tan \delta=0.032$ for $1 \mathrm{~min}$ hold compared to 0.019 and 0.024 respectively for 5 and $10 \mathrm{~min}$ holds). This could be explained by an anticipated surplus of cations left in the films due to the short annealing time. This in turn leads to an increase in leakage current as surplus cations gather in disordered regions of the film, such as grain boundaries, which have been shown to be significant conductive pathways in piezoelectric materials such as BNKT, KNN, and PZT [34-36]. Due to the considerable advantages in terms of thermal budget and only a 


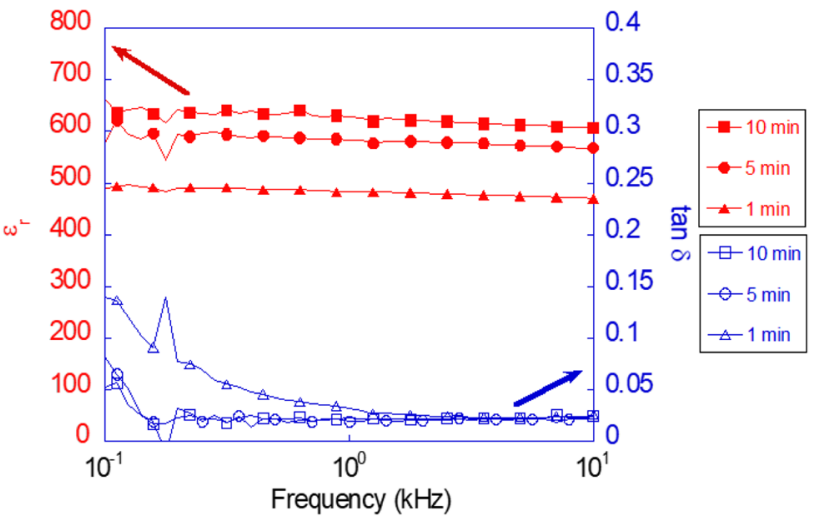

Fig. 3 Dielectric constant $\left(\varepsilon_{\mathrm{r}}\right)$ and dielectric loss ( $\tan \delta$ ) vs. frequency for $210 \mathrm{~nm}$ films annealed for $1 \mathrm{~min}, 5 \mathrm{~min}$, and $10 \mathrm{~min}$ at $700{ }^{\circ} \mathrm{C}$ with a ramp rate of $100^{\circ} \mathrm{C}$ per second

small difference in dielectric constant between the films prepared with 5 and 10 min crystallization steps, the $5 \mathrm{~min}$ step was identified as optimal for further experiments.

The impact of ramp rate on film properties was also observed. Ramp rate is an important factor in processing thin film perovskites due to the potential impact on film defect state and nucleation and growth mechanisms. While the impact of ramp rate on BNT based thin films has not been studied in detail, some studies on other material systems have shown an impact of ramp rate on film nucleation, grain growth and in turn grain size and density. For example Bastani et al. found higher ramp rates in thick PMN-PT films caused them to develop a denser microstructure with larger grains [31] while Velu et al. found that PZT crystallographic orientation was changed from (110) to (100) and grain size was decreased with the use of higher ramp rates compared to conventional thermal annealing [32]. In some material systems faster ramp rates can cause perovskite phases to form at lower temperatures compared to conventional furnace annealing techniques $[33,37]$. Films were crystallized for $5 \mathrm{~min}$ at $700^{\circ} \mathrm{C}$ with ramp rates of $75^{\circ} \mathrm{C}$ per second, $100^{\circ} \mathrm{C}$ per second, $125^{\circ} \mathrm{C}$ per second and $150^{\circ} \mathrm{C}$ per second. Figure 4 shows dielectric constant and loss data for films crystallized using all four ramp rates. Note that no trend in phase purity was observed with ramp rate (all films from the ramp rate had a small amount of second phase via XRD with a low intensity peak observed at a $2 \theta$ of $15^{\circ}$ ).

A considerably higher dielectric loss $(\tan \delta=0.089$ at $1 \mathrm{kHz}$ ) was observed in the $75^{\circ} \mathrm{C}$ per second film compared to films prepared with faster ramp rates $(\tan \delta=0.07,0.06$, and 0.05 at $1 \mathrm{kHz}$ for $100^{\circ} \mathrm{C}$ per second, $125^{\circ} \mathrm{C}$ per second and $150^{\circ} \mathrm{C}$ per second respectively). A slight increase in dielectric constant was observed in the $150^{\circ} \mathrm{C}$ per second film and a slightly higher dielectric loss was observed in the $100^{\circ} \mathrm{C}$ per second film. While the exact reason for the

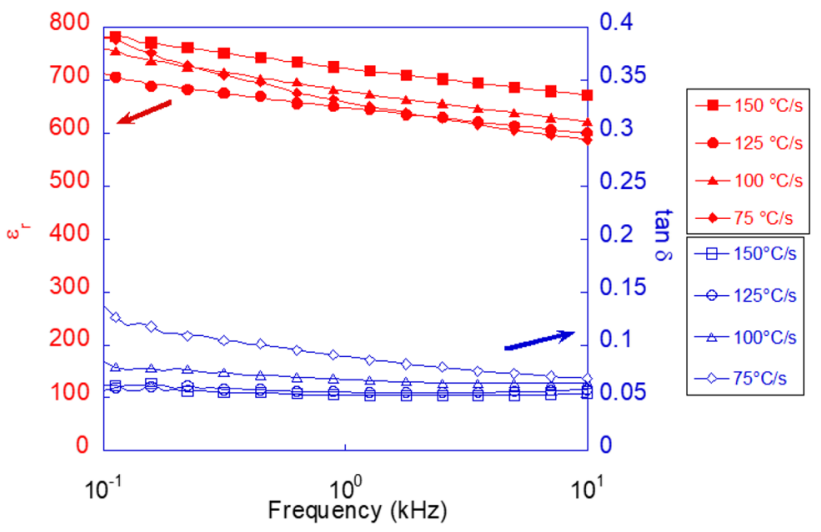

Fig. 4 Dielectric constant $\left(\varepsilon_{\mathrm{r}}\right)$ and dielectric loss (tan $\delta$ ) vs. frequency for $210 \mathrm{~nm}$ films annealed at $700^{\circ} \mathrm{C}$ for 5 min with $75^{\circ} \mathrm{C}$ per second, $100{ }^{\circ} \mathrm{C}$ per second, $125^{\circ} \mathrm{C}$ per second, and $150{ }^{\circ} \mathrm{C}$ per second ramp rates

overall higher losses at slower ramp rates is not entirely clear, it could be related to a change in defect concentration, volatilization behavior, temperature of phase formation, and/or rate of cation volatilization brought about by a change in nucleation and growth mechanisms [31-33].

Strain and P-E loops for films prepared using all ramp rates are shown in Fig. 5.

No obvious trend in polarization behavior was observed with ramp rate. Piezoelectric response was maximized in the $100^{\circ} \mathrm{C}$ per second sample $\left(d_{33, f}=65 \pm 5 \mathrm{pm} / \mathrm{V}\right)$, however, this is only slightly higher than the other ramp rates. More detailed studies are required to determine the exact crystallization mechanisms occurring here and their impact on piezoelectric response.

\subsection{Pyrolysis temperature}

The first heat treatments after spin casting, drying and pyrolysis, can have a major impact on film orientation, density, microstructure, and dielectric constant [38, 39]. During the pyrolysis step organics from the acid/alcoholbased solutions are burned off. If the majority of organics are not removed during the lower temperature pyrolysis step, they can violently volatilize during the high temperature RTA step leaving defects and voids in the films [36]. Figure 6 shows dielectric constant and loss data for films crystallized at $700{ }^{\circ} \mathrm{C}$ for 5 min with a $100^{\circ} \mathrm{C}$ per second ramp rate and pyrolyzed for $4 \mathrm{~min}$ at 300,350 , and $400^{\circ} \mathrm{C}$. Note that hotplate surface temperatures were confirmed with an external thermocouple for these experiments.

Dielectric loss was largely unaffected by pyrolysis temperature. It was observed that dielectric constant increases in the 350 and $400{ }^{\circ} \mathrm{C}$ samples. Dielectric constant at $1 \mathrm{kHz}$ was $450 \pm 50$ at $300^{\circ} \mathrm{C}, 550 \pm 50$ at $350{ }^{\circ} \mathrm{C}$, 
Fig. 5 Strain and P-E response at $1 \mathrm{kHz}$ with $600 \mathrm{kV} / \mathrm{cm}$ maximum applied field for $210 \mathrm{~nm}$ thick films crystallized for 5 min at $700^{\circ} \mathrm{C}$ for a $75^{\circ} \mathrm{C}$ per second $\mathbf{b} 100^{\circ} \mathrm{C}$ per second $\mathbf{c}$ $125^{\circ} \mathrm{C}$ per second and $\mathbf{d} 150^{\circ} \mathrm{C}$ per second. Note $\mathrm{P}_{\text {rrel }}$ represents the relaxed remanent polarization a b

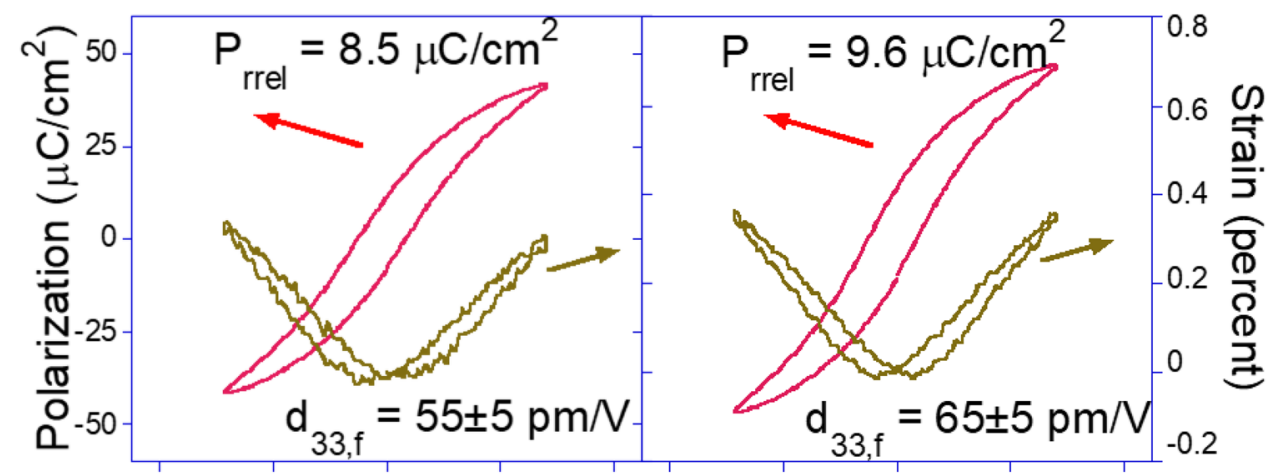

C d

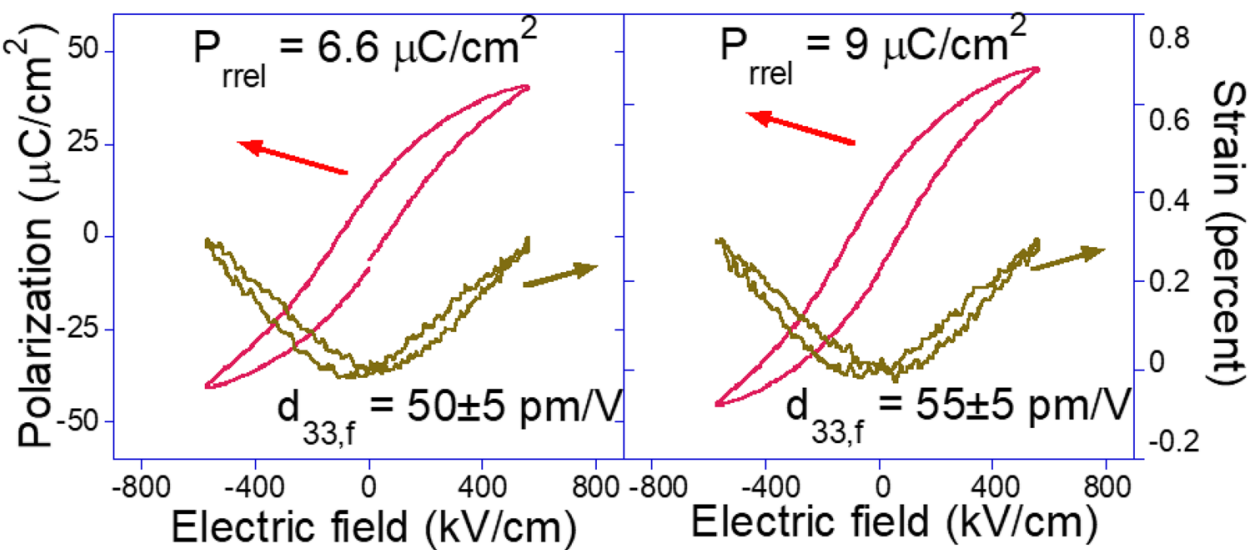

\subsection{Cation excess}

Cation volatility can lead to generation of defects and changes in film composition during high temperature processing, which can ultimately lead to reduced piezoelectric response. One simple but effective method used to counter cation volatility is the inclusion of excess cations within the precursor solution. Typically too little excess gives rise to defects in the form of $\mathrm{Na} / \mathrm{K}$ vacancies as well as oxygen vacancies, while too much excess often leads to a buildup of surplus cations in grain boundaries or the formation of an unwanted second phase [34, 35, 40]. For thin films in general, cation volatility is particularly difficult to control due to very high surface to volume ratio. Here this is exacerbated by the presence of three highly volatile cations; $\mathrm{Bi}, \mathrm{Na}$, and $\mathrm{K}$. Films were prepared with a range of excess $\mathrm{Bi}, \mathrm{Na}$, and $\mathrm{K}$ included during solution preparation. $\mathrm{Bi}$ excess was varied from 6 to $10 \mathrm{~mol} \%$ while $\mathrm{Na}$ and $\mathrm{K}$ excess amounts were varied from 8 to $16 \mathrm{~mol} \%$. In this work, chemical analysis was not performed, however, in previous work, Jeon, et al. performed X-ray photoelectron spectroscopy (XPS) in (1-x)BNKT-xBiMgTiO ${ }_{3}$ films confirming proper relative cation ratios existed in films prepared via chemical solution deposition and crystallized at $700^{\circ} \mathrm{C}$ 
for $10 \mathrm{~min}$ in a conventional box furnace including $10 \%$ excess $\mathrm{Bi}$ and $20 \%$ excess $\mathrm{Na}$ and $\mathrm{K}$, however, some fluctuation in cation amounts was found through the thickness of the films [41].

First the impact of cation excess values on dielectric properties was observed. Figure 7 shows dielectric constant and dielectric loss data for samples prepared with the following excess amounts: $6 \% \mathrm{Bi}$ excess and $8 \% \mathrm{Na}$ and $\mathrm{K}$ excess (6Bi-8Na-8 K), $6 \% \mathrm{Bi}$ excess and $12 \% \mathrm{Na}$ and $\mathrm{K}$ excess $(6 \mathrm{Bi}-12 \mathrm{Na}-12 \mathrm{~K}), 8 \% \mathrm{Bi}$ excess and $8 \% \mathrm{Na}$ and $\mathrm{K}$ excess ( $8 \mathrm{Bi}-8 \mathrm{Na}-8 \mathrm{~K})$, and $8 \% \mathrm{Bi}$ excess and $12 \% \mathrm{Na}$ and $\mathrm{K}$ excess $(8 \mathrm{Bi}-12 \mathrm{Na}-12 \mathrm{~K})$. All samples were $210 \mathrm{~nm}$ thick films annealed for $5 \mathrm{~min}$ at $700^{\circ} \mathrm{C}$ with a $100^{\circ} \mathrm{C}$ per second ramp rate.

Some impact was observed between excess amounts in the dielectric data. A slight increase in dielectric constant and loss was observed in the $8 \mathrm{Bi}-12 \mathrm{Na}-12 \mathrm{~K}$ film (tan $\delta=0.02$ and $\varepsilon_{\mathrm{r}}=500 \pm 50$ at $1 \mathrm{kHz}$ ). This could be attributed to a surplus of $\mathrm{Bi}$ and $\mathrm{Na} / \mathrm{K}$ carriers stacking at grain boundaries under field. Note dielectric constant was lowest in the $8 \mathrm{Bi}-8 \mathrm{Na}-8 \mathrm{~K}$ film $\left(\tan \delta=0.017\right.$ and $\varepsilon_{\mathrm{r}}=450 \pm 50$ at $1 \mathrm{kHz}$ ) which could be due to a change in film stoichiometry brought about by loss of $\mathrm{Na}$ and $\mathrm{K}$ at a faster rate than $\mathrm{Bi}$ during high temperature crystallization. Further work on compositional analysis of these films is necessary to confirm this is the origin of the observed impact on film dielectric properties.

The impact of cation excess on polarization and piezoelectric response was also measured. Figure 8 shows polarization and piezoelectric response vs. electric field for $210 \mathrm{~nm}$ films with varying excess.

The largest measured $d_{33, f}$ value was for the $8 \mathrm{Bi}$ $12 \mathrm{Na}-12 \mathrm{~K}$ film $\left(\mathrm{d}_{33, \mathrm{f}}=65 \pm 5 \mathrm{pm} / \mathrm{V}\right)$, however, this sample

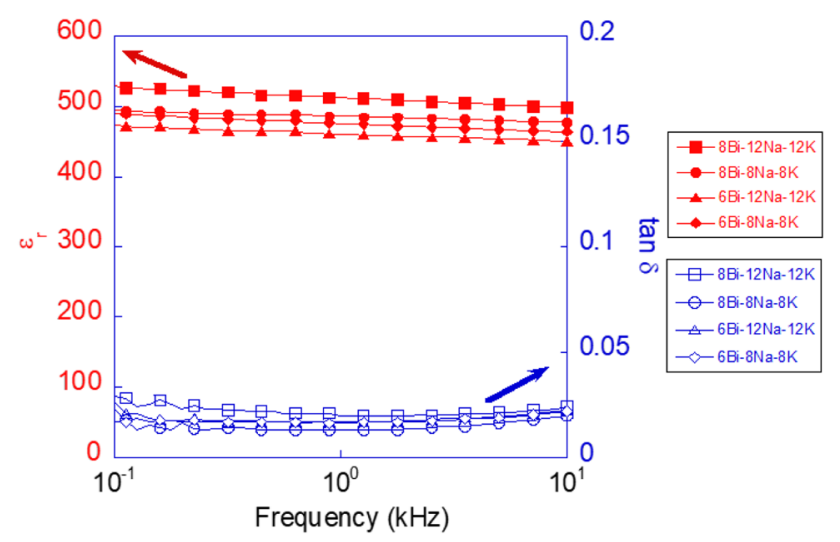

Fig. 7 Dielectric constant $\left(\varepsilon_{\mathrm{r}}\right)$ and dielectric loss (tan $\delta$ ) vs. frequency for $210 \mathrm{~nm}$ thin films crystallized at $700{ }^{\circ} \mathrm{C}$ for $5 \mathrm{~min}$ with varying excess amounts: $6 \% \mathrm{Bi}$ excess and $8 \% \mathrm{Na}$ and $\mathrm{K}$ excess $(\mathbf{6 B i}-$ 8Na-8 K), 6\% Bi excess and $12 \% \mathrm{Na}$ and $\mathrm{K}$ excess (6Bi-12Na-12 K), $8 \% \mathrm{Bi}$ excess and $8 \% \mathrm{Na}$ and $\mathrm{K}$ excess $(\mathbf{8 B i}-\mathbf{8 N a}-\mathbf{8} \mathbf{K})$, and $8 \% \mathrm{Bi}$ excess and $12 \% \mathrm{Na}$ and $\mathrm{K}$ excess (8Bi-12Na-12 K) could not be measured above a field of $300 \mathrm{kV} / \mathrm{cm}$ due to a significant decrease in breakdown strength likely caused by a considerable surplus of cations in film grain boundaries. The piezoelectric constant was maximized without a decrease in breakdown field in the $6 \mathrm{Bi}-12 \mathrm{Na}-12 \mathrm{~K}$ film $\left(\mathrm{d}_{33, \mathrm{f}}=60 \pm 5 \mathrm{pm} / \mathrm{V}\right)$. Films with greater amounts of $\mathrm{Na}$ and $\mathrm{K}$ excess $(6 \mathrm{Bi}-12 \mathrm{Na}-12 \mathrm{~K}$ and $8 \mathrm{Bi}-12 \mathrm{Na}-12 \mathrm{~K}$ ) generally displayed an increase in piezoelectric response of about $10 \mathrm{pm} / \mathrm{V}$ which falls within the general fluctuation in piezoelectric response between sample sets $( \pm 10 \mathrm{pm} / \mathrm{V}$ for 0.8BNT-0.2BKT), however, the increase was observed repeatedly when the experiments were replicated. This increase may be caused by a modification of film stoichiometry during the high temperature crystallization step changing the ultimately realized stoichiometry [34, 35]. $\mathrm{Na}$ and $\mathrm{K}$ are more volatile than $\mathrm{Bi}$ and thus a greater amount of $\mathrm{Na}$ and $\mathrm{K}$ excess must be included in order to control film composition [30]. Slight changes in excess can cause the final film composition to land further from the morphotropic phase boundary, thus leading to reduced structural disorder and in turn reduced strain response. Controlling cation excess is a complicated effort which must be optimized for each particular film synthesis process. Changes in crystallization atmosphere, temperature, time, and changing contamination levels over time in the RTA itself can all impact the optimal excess amounts needed to control film stoichiometry and minimize defect concentration. While the $6 \mathrm{Bi}-12 \mathrm{Na}-12 \mathrm{~K}$ excess was optimal for initial films in a new uncontaminated RTA, after approximately one year of consistent use the chamber was contaminated sufficiently that the annealing atmosphere changed, and a new optimal excess amount was necessary. Evidence of this was observed in XRD scans when a second phase began to appear in $6 \mathrm{Bi}-12 \mathrm{Na}-12 \mathrm{~K}$ films after 14 months of use. Figure 9 shows data from an excess study performed after the initial appearance of this phase impurity.

Films made with lower excess amounts $(6 \mathrm{Bi}-8 \mathrm{Na}-8 \mathrm{~K}$ and $6 \mathrm{Bi}-10 \mathrm{Na}-10 \mathrm{~K}$ ) were phase pure while the previously optimal $6 \mathrm{Bi}-12 \mathrm{Na}-12 \mathrm{~K}$ film displayed a second phase (circled in the figure). As such, it is important when designing a CSD process for BNKT thin films that excess amounts not just be initially optimized but tested and adjusted over time.

\section{Conclusion}

Inverse mixing order chemical solution deposition methods for lead-free thin films are of particular interest to industry due to scalability and use of non-toxic precursors. This study presents experimental data on process optimization for BNKT thin films focusing on actuator properties. Phase pure perovskite BNKT (0.8BNT-0.2BKT) thin films 
Fig. 8 Strain and P-E response at $1 \mathrm{kHz}$ for $210 \mathrm{~nm}$ thin films crystallized at $700{ }^{\circ} \mathrm{C}$ for $5 \mathrm{~min}$ with a $6 \% \mathrm{Bi}$ excess and $8 \% \mathrm{Na}$ and $\mathrm{K}$ excess $(\mathbf{6 B i}-\mathbf{8} \mathbf{N a}-\mathbf{8} \mathrm{K}), \mathbf{b}$ $8 \% \mathrm{Bi}$ excess and $8 \% \mathrm{Na}$ and $\mathrm{K}$ excess (8Bi-8Na-8 K) c 6\% $\mathrm{Bi}$ excess and $12 \% \mathrm{Na}$ and $\mathrm{K}$ excess (6Bi-12Na-12 K), and d $8 \% \mathrm{Bi}$ excess and $12 \% \mathrm{Na}$ and $\mathrm{K}$ excess (8Bi-12Na-12 K). Note $P_{\text {rrel }}$ represents the remanent polarization

\section{a}

b
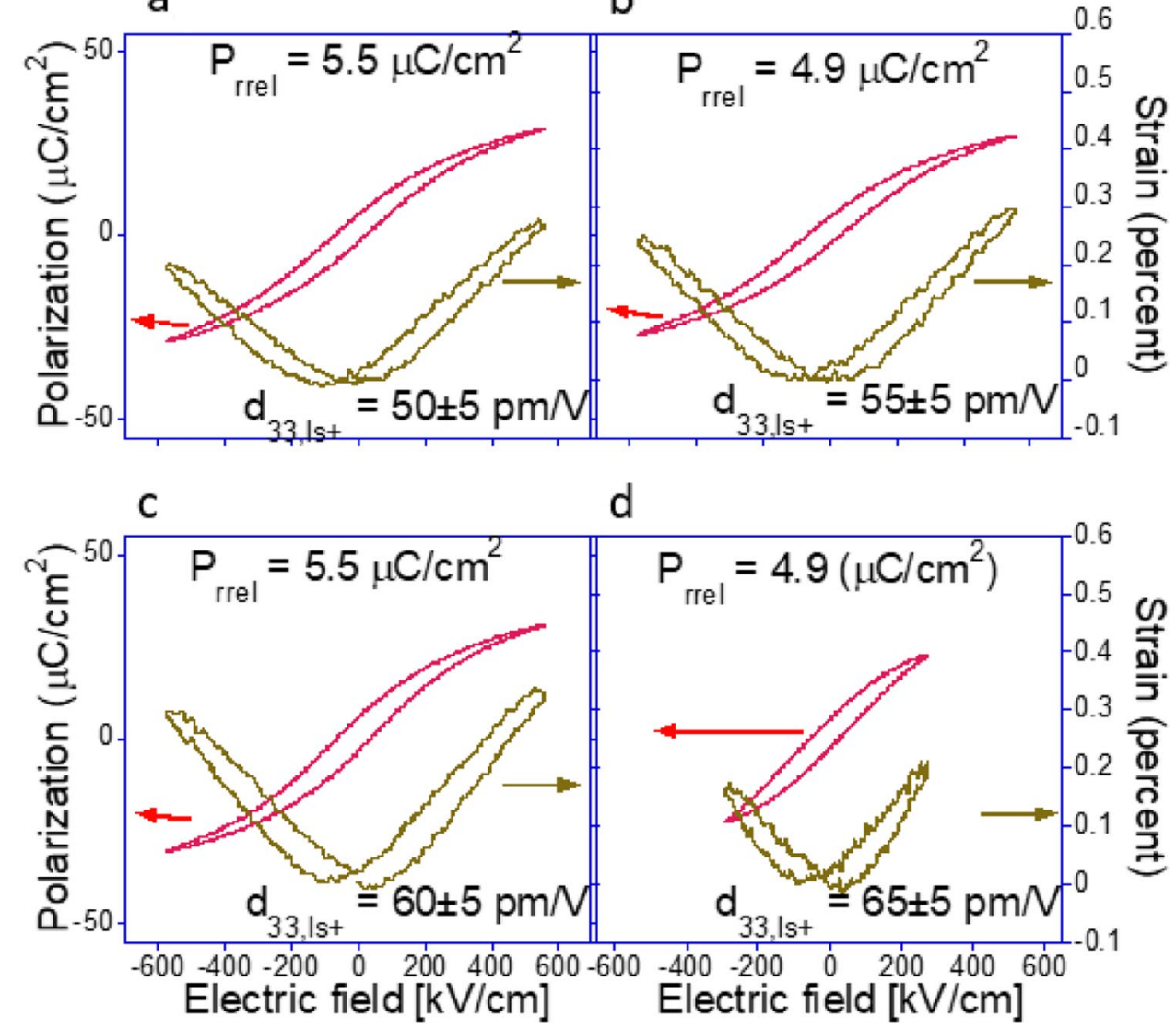

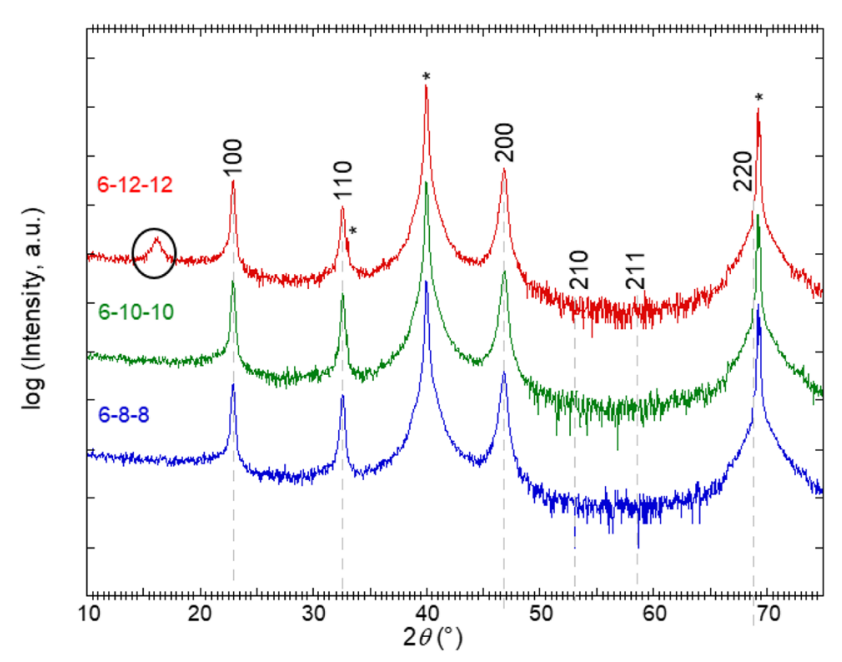

Fig. 9 XRD data from an excess study performed after contamination of RTA chamber for films crystallized at $700{ }^{\circ} \mathrm{C}$ for 5 min with varying excess amounts: $6 \% \mathrm{Bi}$ excess and $8 \% \mathrm{Na}$ and $\mathrm{K}$ excess (6Bi$\mathbf{8 N a - 8 ~ K ) , 6 \% ~ B i ~ e x c e s s ~ a n d ~} 10 \% \mathrm{Na}$ and $\mathrm{K}$ excess (6Bi-10Na-10 K), and $6 \% \mathrm{Bi}$ excess and $12 \% \mathrm{Na}$ and $\mathrm{K}$ excess (6Bi-12Na-12 K) with present BNKT peaks labeled (* was used to mark substrate peaks) were successfully prepared via an inverse mixing order chemical solution deposition process. Experiments were performed to evaluate the impact of process conditions on key film properties including phase purity, dielectric constant and loss, ferroelectric response, and piezoelectric strain. Crystallization temperatures of 600,700 , and $800^{\circ} \mathrm{C}$ all produced phase pure perovskites. Crystallization times of five minutes or greater are required to maximize dielectric constant $\left(\varepsilon_{\mathrm{r}}\right.$ at $1 \mathrm{kHz}=600 \pm 50$ for a 10 -min hold). Piezoelectric response was maximized in films prepared using a $100^{\circ} \mathrm{C}$ per second ramp rate $\left(d_{33, \mathrm{f}}=65 \pm 5 \mathrm{pm} / \mathrm{V}\right.$ at $1 \mathrm{kHz})$. Pyrolysis temperatures greater than $350^{\circ} \mathrm{C}$ showed an increase in dielectric constant from $450 \pm 50$ at $1 \mathrm{kHz}$ for a $300{ }^{\circ} \mathrm{C}$ pyrolysis step to a maximum of $600 \pm 50$ at $1 \mathrm{kHz}$ for a $400{ }^{\circ} \mathrm{C}$ pyrolysis step. Excess cations should be employed in order to maintain BNKT film stoichiometry during high temperature crystallization. An increase of about $10 \mathrm{pm} / \mathrm{V}$ was observed in $\mathrm{d}_{33, \mathrm{f}}$ for films prepared with greater amounts of sodium and potassium excess relative to $\mathrm{Bi}$ excess. The inclusion of too much total excess cations can lead to a considerable decrease in observed breakdown field from about $800 \mathrm{kV} / \mathrm{cm}$ to about $300 \mathrm{kV} /$ $\mathrm{cm}$. Excess amounts must be adjusted as annealing atmosphere and conditions change over time in order to synthesize BNKT films with desired final stoichiometry. These 
results may prove useful to those developing inverse mixing order processes for the fabrication of bismuth based thin film materials.

Funding The authors wish to acknowledge Xaar plc (Cambridge, UK) for their support for this research project.

\section{Declarations}

Conflict of interest On behalf of all authors, the corresponding author states that there is no conflict of interest.

Open Access This article is licensed under a Creative Commons Attribution 4.0 International License, which permits use, sharing, adaptation, distribution and reproduction in any medium or format, as long as you give appropriate credit to the original author(s) and the source, provide a link to the Creative Commons licence, and indicate if changes were made. The images or other third party material in this article are included in the article's Creative Commons licence, unless indicated otherwise in a credit line to the material. If material is not included in the article's Creative Commons licence and your intended use is not permitted by statutory regulation or exceeds the permitted use, you will need to obtain permission directly from the copyright holder. To view a copy of this licence, visit http://creativecommons. org/licenses/by/4.0/.

\section{References}

1. Shibata K, Wang R, Tou T, Koruza J (2018) Applications of leadfree piezoelectric materials. MRS Bull 43(8):612-616. https://doi. org/10.1557/mrs.2018.180

2. Zhang S, Xia R, Shrout TR (2007) Lead-free piezoelectric ceramics vs. PZT. Journal Electroceramics 19(4):251-257. https://doi.org/ $10.1007 / \mathrm{s} 10832-007-9056-z$

3. Safari A, Abazari M (2010) Lead-free piezoelectric ceramics and thin films. IEEE Trans Ultrasonic Ferroelectric Freq Control 57(10):2165-2176. https://doi.org/10.1109/TUFFC.2010.1674

4. DIRECTIVE 2011/65/EU OF THE EUROPEAN PARLIAMENT AND OF THE COUNCIL of 8 June 2011 on the restriction of the use of certain hazardous substances in electrical and electronic equipment. https://eur-lex.europa.eu/legal-content/EN/ TXT/?uri=CELEX:32011L0065

5. Sasaki A, Chiba T, Mamiya Y, Otsuki E (1999) Dielectric and piezoelectric properties of $\left(\mathrm{Bi}_{0.5} \mathrm{Na}_{0.5}\right) \mathrm{TiO}_{3}-\left(\mathrm{Bi}_{0.5} \mathrm{~K}_{0.5}\right) \mathrm{TiO}_{3}$ systems. Jpn J Appl Phys 38(9B):5564-5567. https://doi.org/10.1143/JJAP.38. 5564

6. Patterson EA, Cann DP, Pokorny J, Reaney IM (2012) Electromechanical strain in $\mathrm{Bi}\left(\mathrm{Zn}_{1 / 2} \mathrm{Ti}_{1 / 2}\right) \mathrm{O}_{3}-\left(\mathrm{Bi}_{1 / 2} \mathrm{Na}_{1 / 2}\right) \mathrm{TiO}_{3}-\left(\mathrm{Bi}_{1 / 2} \mathrm{~K}_{1 / 2}\right) \mathrm{TiO}_{3}$ solid solutions. J Appl Phys 111(9):094105. https://doi.org/10. 1063/1.4714346

7. Kumar N, Cann DP (2013) Electromechanical strain and bipolar fatigue in $\mathrm{Bi}\left(\mathrm{Mg}_{1 / 2} \mathrm{Ti}_{1 / 2}\right) \mathrm{O}_{3}-\left(\mathrm{Bi}_{1 / 2} \mathrm{~K}_{1 / 2}\right) \mathrm{TiO}_{3}-\left(\mathrm{Bi}_{1 / 2} \mathrm{Na}_{1 / 2}\right) \mathrm{TiO}_{3}$ ceramics. J Appl Phys 114(5):054102. https://doi.org/10.1063/1.48175 24

8. Seifert KTP, Jo W, Rödel J (2010) Temperature-insensitive large strain of $(\mathrm{Bi} 1 / 2 \mathrm{Na} 1 / 2) \mathrm{TiO} 3-(\mathrm{Bi} 1 / 2 \mathrm{~K} 1 / 2) \mathrm{TiO} 3-(\mathrm{K} 0.5 \mathrm{Na} 0.5) \mathrm{NbO} 3$ lead-free piezoceramics. J Am Ceram Soc. https://doi.org/10. 1111/j.1551-2916.2009.03573.x

9. Zhang $X$ et al (2018) Mn doping effects on electric properties of $0.93\left(\mathrm{Bi}_{0.5} \mathrm{Na}_{0.5}\right) \mathrm{TiO}_{3}-0.07 \mathrm{Ba}\left(\mathrm{Ti}_{0.945} \mathrm{Zr}_{0.055}\right) \mathrm{O}_{3}$ ceramics. J Am Ceram Soc 101(7):2996-3004. https://doi.org/10.1111/jace. 15457
10. Wu Y, Or SW (2018) Thickness-dependent structural and electromechanical properties of $\left(\mathrm{Na}_{0.85} \mathrm{~K}_{0.15}\right)_{0.5} \mathrm{Bi}_{0.5} \mathrm{TiO}_{3}$ multilayer thin film-based heterostructures. Material Des 149:153-164. https:// doi.org/10.1016/j.matdes.2018.04.012

11. Jeon YH, Patterson EA, Cann DP, Gibbons BJ (2013) Dielectric and ferroelectric properties of $\left(\mathrm{Bi}_{0.5} \mathrm{Na}_{0.5}\right) \mathrm{TiO}_{3}-\left(\mathrm{Bi}_{0.5} \mathrm{~K}_{0.5}\right) \mathrm{TiO}_{3}-\mathrm{BaTiO}_{3}$ thin films deposited via chemical solution deposition. Mater Lett 106:63-66. https://doi.org/10.1016/j.matlet.2013.04.096

12. Jeon YH, Patterson EA, Cann DP, Mardilovich P, Stickel W, Gibbons $B J$ (2013) Large piezoresponse and ferroelectric properties of $\left(\mathrm{Bi}_{0.5} \mathrm{Na}_{0.5}\right) \mathrm{TiO}_{3}-\left(\mathrm{Bi}_{0.5} \mathrm{~K}_{0.5}\right) \mathrm{TiO}_{3}-\mathrm{Bi}\left(\mathrm{Mg}_{0.5}-\mathrm{Ti}_{0.5}\right) \mathrm{O}_{3}$ thin films prepared by chemical solution deposition. J Am Ceram Soc 96(7):2172-2178. https://doi.org/10.1111/jace.12279

13. Walenza-Slabe J, Gibbons BJ (2017) Effect of annealing atmosphere $\mathrm{pO} 2$ on leakage current in $80(\mathrm{Bi0} .5 \mathrm{Na0.5}) \mathrm{TiO} 3-$ 20(Bi0.5K0.5)TiO3 piezoelectric thin films. Appl Phys Lett 110(16):162904. https://doi.org/10.1063/1.4981771

14. Abazari M, Safari A, Bharadwaja SSN, Trolier-McKinstry S (2010) Dielectric and piezoelectric properties of lead-free $(\mathrm{Bi}, \mathrm{Na})$ $\mathrm{Ti}_{\mathrm{O}}$ 3-based thin films. Appl Phys Lett 96(8):082903. https:// doi.org/10.1063/1.3309706

15. Ahn CW, Won SS, Ullah A, Lee SY, Lee SD, Lee JH, Jo W, Kim IW (2012) Large piezoresponse of lead-free $\mathrm{Bi}_{0.5}\left(\mathrm{Na}_{0.85} \mathrm{~K}_{0.15}\right)_{0.5} \mathrm{TiO}_{3}$ thin film. Curr Appl Phys 12(3):903-907. https://doi.org/10. 1016/j.cap.2011.12.005

16. Cui W, Wang X, Li L (2015) Large piezoresponse of $\mathrm{Na}_{0.5} \mathrm{Bi}_{0.5} \mathrm{TiO}_{3}-\mathrm{K}_{0.5} \mathrm{Bi}_{0.5} \mathrm{TiO}_{3}$ thin films prepared via water-based sol-gel method. Ceram Int 41:S37-S40. https://doi.org/10. 1016/j.ceramint.2015.03.232

17. Acharya SK, Kim T-M, Hyung J-H, Ahn B-G, Lee S-K (2014) Ferroelectric and piezoelectric properties of lead-free $\mathrm{Bi}_{0.5} \mathrm{Na}_{0.5} \mathrm{TiO}_{3}-\mathrm{Bi}_{0.5} \mathrm{~K}_{0.5} \mathrm{TiO}_{3}-\mathrm{BaTiO}_{3}$-thin films near the morphotropic phase boundary. J Alloys Compd 586:549-554. https:// doi.org/10.1016/j.jallcom.2013.10.028

18. Li W, Zeng H, Zhao K, Hao J, Zhai J (2014) Structural, dielectric and piezoelectric properties of $\left(\mathrm{Bi}_{0.5} \mathrm{Na}_{0.5}\right) \mathrm{TiO}_{3}-\left(\mathrm{Bi}_{0.5} \mathrm{~K}_{0.5}\right) \mathrm{TiO}_{3}-$ $\mathrm{Bi}\left(\mathrm{Zn}_{0.5} \mathrm{Ti}_{0.5}\right) \mathrm{O}_{3}$ thin films prepared by sol-gel method. Ceram Int 40(6):7947-7951. https://doi.org/10.1016/j.ceramint.2013. 12.143

19. Li W, Zeng H, Hao J, Zhai J (2013) Enhanced dielectric and piezoelectric properties of $\mathrm{Mn}$ doped $\left(\mathrm{Bi}_{0.5} \mathrm{Na}_{0.5}\right) \mathrm{TiO}_{3}-\left(\mathrm{Bi}_{0.5} \mathrm{~K}_{0.5}\right)$ $\mathrm{TiO}_{3}-\mathrm{SrTiO}_{3}$ thin films. J Alloys Compd 580:157-161. https:// doi.org/10.1016/j.jallcom.2013.05.127

20. Wenhan C, Xiaohui W, Yunyi W, Yun-Gang L, Longtu L (2016) Investigation of thickness dependence of electric properties of sol-gel BNT-BT thin films with stepwise crystallization. J Ceram Soc Jpn 124(4):464-468. https://doi.org/10.2109/jcers j2.15315

21. Quan ND, Hung VN, Dung DD (2017) Influence of film thickness on ferroelectric properties and leakage current density in lead-free Bi0.5(Na0.80K0.20)0.5TiO3 films. Mater Res Express 4(8):086401. https://doi.org/10.1088/2053-1591/aa7b43

22. Onishi R, Ogawa $H$, lida D, Kan A (2017) Synthesis and piezoelectric properties of (1-x)Bi0.5(Na0.8K0.2)0.5TiO3-xSr2ZrTiO6 ceramics. Jpn J Appl Phys 56(10S):10PD04. https://doi.org/10. 7567/JJAP.56.10PD04

23. Zhou Z, Sun W, Li J-F (2016) Sol-gel synthesis of $0.94\left(\mathrm{Bi}_{0.5} \mathrm{Na}_{0.5}\right)$ $\mathrm{TiO}_{3}-0.06 \mathrm{BaTiO}_{3}$ lead-free piezoelectric films: effect of pyrolysis temperature on phase evolution and electrical properties. J Sol-Gel Sci Technol 77(2):423-429. https://doi.org/10.1007/ s10971-015-3870-6

24. Yao Y, Wu X, Shi P, Ye Z-G (2016) Effects of heat-treatment temperature on the properties of $(1-\mathrm{x})(\mathrm{Na0} 0.5 \mathrm{Bi} 0.5) \mathrm{TiO} 3-\mathrm{xBiAlO} 3$ Lead-free piezoelectric thin films. J Am Ceram Soc 99(4):13401344. https://doi.org/10.1111/jace.14116 
25. Yang CH, Yao Q, Qian J, Han YJ, Chen J (2018) Growth, microstructure, energy-storage and dielectric performances of chemical-solution NBT-based thin films: effect of sodium nonstoichiomometry. Ceram Int 44(8):9152-9158. https:// doi.org/10.1016/j.ceramint.2018.02.123

26. Dargham SA, Ponchel F, Abboud N, Soueidan M, Ferri A, Desfeux R, Assad J, Remiens D, Zaouk D (2018) Synthesis and electrical properties of lead-free piezoelectric $\mathrm{Bi}_{0.5} \mathrm{Na}_{0.5} \mathrm{TiO}_{3}$ thin films prepared by Sol-Gel method. J Eur Ceram Soc 38(4):1450-1455. https://doi.org/10.1016/j.jeurceramsoc. 2017.06.019

27. Sivaramakrishnan S, Mardilovich $P$, Mason A, Roelofs A, Schmitz-Kempen T, Tiedke S (2013) Electrode size dependence of piezoelectric response of lead zirconate titanate thin films measured by double beam laser interferometry. Appl Phys Lett 103(13):132904. https://doi.org/10.1063/1.4821948

28. Reichmann K, Feteira A, Li M (2015) Bismuth sodium titanate based materials for piezoelectric actuators. Materials 8(12):8467-8495. https://doi.org/10.3390/ma8125469

29. Sivaramakrishnan S, Mardilovich P, Schmitz-Kempen T, Tiedke S (2018) Concurrent wafer-level measurement of longitudinal and transverse effective piezoelectric coefficients $\left(d_{33}, f\right.$ and $\left.{ }_{e 31}, f\right)$ by double beam laser interferometry. J Appl Phys 123(1):014103. https://doi.org/10.1063/1.5019568

30. Honig RE (1957) Vapor pressure data for the more common elements. RCA Rev 18:195-204

31. Bastani Y, Bassiri-Gharb N (2012) Processing optimization of lead magnesium niobate-lead titanate thin films for piezoelectric MEMS application. J Am Ceram Soc 95(4):1269-1275. https:// doi.org/10.1111/j.1551-2916.2011.05042.x

32. Velu G, Remiens D, Thierry B (1997) Ferroelectric properties of PZT thin films prepared by sputtering with stoichiometric single oxide target: Comparison between conventional and rapid thermal annealing. Journal Eur Ceram Soc 17(14):1749-1755. https://doi.org/10.1016/S0955-2219(97)00031-9

33. Dang EKF, Gooding RJ (1995) Theory of the effects of rapid thermal annealing on thin-film crystallization. Phys Rev Lett 74(19):3848-3851. https://doi.org/10.1103/PhysRevLett.74.3848
34. Wu Y, Wang $X$, Zhong $C$, Li L (2011) Effect of $\mathrm{Na} / \mathrm{K}$ excess on the electrical properties of $\mathrm{Na}_{0.5} \mathrm{Bi}_{0.5} \mathrm{TiO}_{3}-\mathrm{K}_{0.5} \mathrm{Bi}_{0.5} \mathrm{TiO}_{3}$ thin films prepared by sol-gel processing. Thin Solid Films 519(15):47984803. https://doi.org/10.1016/j.tsf.2011.01.077

35. Ahn CW, Lee SY, Lee HJ, Ullah A, Bae JS, Jeong ED, Choi JS, Park $\mathrm{BH}, \mathrm{Kim}$ IW (2009) The effect of $\mathrm{K}$ and $\mathrm{Na}$ excess on the ferroelectric and piezoelectric properties of $\mathrm{K} 0.5 \mathrm{Na} 0.5 \mathrm{NbO} 3$ thin films. Journal of Applied Physics. 42(21):215304. https://doi.org/10. 1088/0022-3727/42/21/215304

36. Arai T, Ohno T, Matsuda T, Sakamoto N, Wakiya N, Suzuki H (2015) Effects of synthesis conditions on electrical properties of chemical solution deposition-derived $\mathrm{Pb}\left(\mathrm{Mg}_{1 / 3} \mathrm{Nb}_{2 / 3}\right) \mathrm{O}_{3}-\mathrm{PbTiO}_{3}$ thin films. Thin Solid Films 585:86-90. https://doi.org/10.1016/j.tsf. 2014.11.014

37. Li Y, Zhang S, Fei W, Wang $\mathrm{H}$ (2008) Crystallization behavior of $\mathrm{Nd}$-doped $\mathrm{SrBi}_{2} \mathrm{Ta}_{2} \mathrm{O}_{9}$ thin films prepared by magnetron sputtering. Thin Solid Films 516(16):5252-5257. https://doi.org/10. 1016/j.tsf.2007.07.054

38. Yu Q, Li J, Chen Y, Cheng L, Sun W, Zhou Z, Wang Z (2014) Effect of pyrolysis temperature on Sol-Gel synthesis of lead-free piezoelectric $(\mathrm{K}, \mathrm{Na}) \mathrm{Nb}_{\mathrm{O}} 3$ films on $\mathrm{Nb}: \mathrm{SrTi}_{\mathrm{O}} 3$ substrates. J Am Ceram Soc 97(1):107-113. https://doi.org/10.1111/jace.12675

39. Gong W, Li J-F, Chu X, Li L (2004) Effect of pyrolysis temperature on preferential orientation and electrical properties of sol-gel derived lead zirconate titanate films. J Eur Ceram Soc 24(1011):2977-2982. https://doi.org/10.1016/j.jeurceramsoc.2003.10. 007

40. Khokhar A, Goyal PK, Thakur OP, Sreenivas K (2015) Effect of excess of bismuth doping on dielectric and ferroelectric properties of $\mathrm{BaBi}_{4} \mathrm{Ti}_{4} \mathrm{O}_{15}$ ceramics. Ceram Int 41(3):4189-4198. https:// doi.org/10.1016/j.ceramint.2014.12.103

41. Jeon YH (2012) Development of Bi-based lead-free piezoelectric materials: thin film piezoelectric materials via PVD and CSD routes, Dissertation, Oregon State University

Publisher's Note Springer Nature remains neutral with regard to jurisdictional claims in published maps and institutional affiliations. 